\title{
Prediction of posthepatectomy liver failure using transient elastography in patients with hepatitis $B$ related hepatocellular carcinoma
}

\author{
Jie-wen Lei ${ }^{1 \dagger}$, Xiao-yu $\mathrm{Ji}^{2+}$, Jun-feng Hong ${ }^{1,3+}$, Wan-bin $\mathrm{Li}^{4}$, Yan Chen ${ }^{1}$, Yan Pan ${ }^{5}$ and Jia Guo ${ }^{1 *}$ (D)
}

\begin{abstract}
Background: It is essential to accurately predict Postoperative liver failure (PHLF) which is a life-threatening complication. Liver hardness measurement (LSM) is widely used in non-invasive assessment of liver fibrosis. The aims of this study were to explore the application of preoperative liver stiffness measurements (LSM) by transient elastography in predicting postoperative liver failure (PHLF) in patients with hepatitis B related hepatocellular carcinoma.

Methods: The study included 247 consecutive patients with hepatitis B related hepatocellular carcinoma who underwent hepatectomy between May 2015 and September 2015. Detailed preoperative examinations including LSM were performed before hepatectomy. The endpoint was the development of PHLF.

Results: All of the patients had chronic hepatitis B defined as the presence of hepatitis B surface antigen (HBsAg) for more than 6 months and 76 (30.8\%) had cirrhosis. PHLF occurred in 37 (14.98\%) patients. Preoperative LSM (odds ratio, OR, 1.21; 95\% confidence interval, 95\% Cl: 1.13-1.29; $P<0.001)$ and international normalized ratio (INR) (OR, 1.07; 95\% Cl: $1.01-1.12 ; P<0.05)$ were revealed to be independent risk factors for PHLF, and a new model was defined as LSMINR index (LSM-INR index $=0.191^{*} \mathrm{LSM}+6.317^{*}$ INR-11.154). The optimal cutoff values of LSM and LSM-INR index for predicting PHLF were $14 \mathrm{kPa}$ (AUC 0.86, 95\% Cl: 0.811-0.901, $P<0.001$ ) and -1.92 (AUC 0.87, 95\% Cl: 0. 822-0.909, $P<0.001)$, respectively.
\end{abstract}

Conclusions: LSM can be helpful for surgeons to make therapeutic decisions in patients with hepatitis $B$ related hepatocellular carcinoma.

Keywords: Hepatocellular carcinoma, Hepatectomy, Posthepatectomy liver failure, Liver stiffness measurement, Hepatitis B

\section{Background}

Hepatocellular carcinoma (HCC) is one of the common malignant tumors worldwide. Surgical resection is the most effective treatment for patients with localized HCC $[1,2]$. However, postoperative liver failure (PHLF) is a life-threatening complication and intrinsic risk of mortality [3]. It is not only correlated with the volumes of

\footnotetext{
* Correspondence: jia_guo@163.com

Jie-wen Lei, Xiao-yu Ji and Jun-feng Hong contributed equally to this work. ${ }^{\dagger}$ Equal contributors

${ }^{1}$ Department of Ultrasound, Eastern Hepatobiliary Surgery Hospital (EHBH), Second Military Medical University, Shanghai, China

Full list of author information is available at the end of the article
}

liver resection, but also the insufficient function of hepatic reserve (FHR) [4].

More than $80 \%$ of HCCs arise in patients with hepatic fibrosis or cirrhosis [5], which has a very important impact on liver function [4]. Hence, we attempted to determine whether FHR can be indirectly predicted by assessing the degree of liver fibrosis.

LSM is a technology involving obtaining the liver instantaneous elastic modulus to estimate the degree of liver fibrosis by transient elastography (TE), an easy and noninvasive method with high accuracy [6-8].

Recently, several studies reported that liver stiffness is associated with posthepatectomy outcomes [10-12]. 
However, baseline characteristics of patients differed greatly among these studies, and few of the studies focused on PHLF. Unlike those in the western countries, about $80 \%$ HCC patients in China had hepatitis B virus infection [13].

\section{Aim of the study}

In this study, we aimed to assess the usefulness of liver stiffness measured by transient elastography Fibro Touch ${ }^{\circ}$ (Wuxi HISKY Medical Technologies Co., Ltd. Beijing, China) for predicting PHLF in patients with hepatitis B-related hepatocellular carcinoma.

\section{Methods}

\section{Patients}

This study was approved by the Institutional Ethics Committee of the Eastern Hepatobiliary Surgery Hospital (EHBH).

$\mathrm{HCC}$ patients who underwent liver resection at $\mathrm{EHBH}$ were prospectively recruited between May 2015 and September 2015. The exclusion criteria were as follows: (i) patients with hepatolithiasis or patients who will receive hepatectomy because of intrahepatic cholangiocarcinoma (ICC) or hepatic maligancies other than HCC; (ii) patients with cirrhosis due to schistosomiasis, alcoholic liver disease or non-alcoholic fatty liver disease (NAFLD); (iii) patients undergoing preoperative transhepatic arterial chem otherapy and embolization (TACE).

\section{Transient elastography}

All patients fasted for at least $6 \mathrm{~h}$ before receiving LSM examination by transient elastography FibroTouch ${ }^{\circ}$. The examination was performed by two trained and certified operators who were blinded to the patients' clinical data, according to the operation manual and the Liver Stiffness Study Group "Elastica" of the Italian Association for the Study of the Liver [14]. LSM was expressed in kiloPascals $(\mathrm{kPa})$ and was considered reliable only if 10 successful measurements were obtained, with an IQR/median of LSM of $<30 \%$ and a success rate of $>60 \%$ [15].

\section{Liver surgery}

During surgery, right costal margin incision was chosen and the fluid infusion was minimal to keep central venous pressure lower than $5 \mathrm{mmHg}$ to reduce bleeding from hepatic veins $[16,17]$. Intraoperative ultrasound (US) was performed systematically to detect the presence of any additional nodules not detected preoperatively. Major hepatectomy was defined as removal of 3 or more Couinaud segments [18, 19]. Diuretics and Ampicillin were used for routine postoperative care.

PHLF was defined as the presence of at least one of the following variables: 1) occurrence of refractory ascites causing a delay in the removal of surgical drainages and/or postoperative drainage exceeding $500 \mathrm{ml} /$ day, a continuous elevation of total serum bilirubin concentration ( $\geq 60 \mathrm{umol} /$ l) beyond postoperative day $7 ; 2$ ) alteration of coagulation factors requiring fresh frozen plasma infusion with an International Normalized Ratio (INR) of more than 1.50 [20]. The endpoint of this study is the presence of PHLF.

\section{Statistical analysis}

Continuous variables were expressed as the mean and standard deviation. Differences between the subgroups were compared by $t$-test or Mann-Whitney $\mathrm{U}$ test.

Table 1 Baseline characteristics of patients $(N=247)$

\begin{tabular}{|c|c|}
\hline Variables & $\begin{array}{l}\mathrm{n}(\%), \text { mean } \pm \mathrm{SD} \text {, or median } \\
\text { (range) }\end{array}$ \\
\hline Age (years) & $53.3 \pm 10.3$ \\
\hline Gender (Male /Female) & 213/34(86\%/14\%) \\
\hline $\mathrm{BMI}(\mathrm{kg} / \mathrm{m} 2)$ & $29.9 \pm 16.5$ \\
\hline Complications $^{a}$ & $43(17 \%)$ \\
\hline Cirrhosis (yes /no) & 76/171(30.8\%/69.2\%) \\
\hline White blood cell $\left(10^{9} / l\right)$ & $5.2 \pm 2.0$ \\
\hline Hemoglobin $(\mathrm{g} / \mathrm{l})$ & $143.9 \pm 14.1$ \\
\hline Platelet Count $\left(10^{9} / \mathrm{l}\right)$ & $145(41-466)$ \\
\hline Child-Pugh class A & 247 \\
\hline Total bilirubin (umol/l) & $16.0 \pm 11.8$ \\
\hline Albumin $(g / l)$ & $41.7 \pm 3.3$ \\
\hline Prealbumin (mg/l) & $238.6 \pm 62.6$ \\
\hline Alanine transaminase $(\mathrm{u} / \mathrm{l})$ & $39.2 \pm 34.2$ \\
\hline Aspartate aminotransferase (u/l) & $36.99 \pm 31.3$ \\
\hline Gamma-glutamyl transpeptidase (u/l) & $47(11-866)$ \\
\hline Alkaline phosphatase (u/l) & $81(34-250)$ \\
\hline PT(s) & 11.5(9.4-15.4) \\
\hline INR & $1.0(0.8-1.3)-$ \\
\hline APTT(s) & $27.2(16.7-52.9)$ \\
\hline LSM(Kpa) & $12.7(3.8-38.5)$ \\
\hline Intraoperative blood infusion (yes / no) & $19 / 228(8 \% / 92 \%)$ \\
\hline Portal vein occlusion (yes / no) & 194/53(79\%/21\%) \\
\hline Esophageal varices (yes / no) & 18/229(7.3\%/92.7\%) \\
\hline Tumor capsule (yes / no) & 174/73(70\%/30\%) \\
\hline Number of tumors (Single / multiple) & $217 / 30(88 \% / 12 \%)$ \\
\hline Anti-viral medication(Positive / negative) & 71/176(28.7\%/71.2\%) \\
\hline $\begin{array}{l}\text { HBV DNA levels }(>1.0 \mathrm{E}+04 \mathrm{iu} / \mathrm{ml} /<1.0 \mathrm{E}+ \\
04 \mathrm{iu} / \mathrm{ml})\end{array}$ & 73/174(30\%/70\%) \\
\hline Major hepatectomy & $40(16 \%)$ \\
\hline Median main tumor size $(\mathrm{cm})$ & $5.02 \pm 3.18$ \\
\hline $\begin{array}{l}\text { Tumor location (right lobe /left lobe/ } \\
\text { both) }\end{array}$ & 158/79/10(64\%/32\%/4\%) \\
\hline
\end{tabular}

${ }^{a}$ Complications include one or more of the following: hypertension, heart disease (myocardial ischemia, cardiomyopathy, arrhythmia), chronic obstructive pulmonary disease, diabetes, etc. 
Categorical variables were compared using $X^{2}$ test with Yates' correction or Fisher's exact test. Factors with significant impact on PHLF upon univariate analysis were explored with multivariate forward logistic regression as hypothetical independent predictors of PHLF. A significance level of 0.05 was used in all analyses. The prognostic value of PHLF prediction model and the LSM only were assessed using receiver operating characteristic (ROC) curve analysis (MedCalc Software bvba, Ostend, Belgium). The area under the ROC curve (AUC), the sensitivity, the specificity, the positive and negative predictive values, and the positive and negative likelihood ratio for cutoff values were obtained.

Data analysis was performed using SPSS, version 19.0 for Windows (SPSS, Inc., Chicago, IL) and R software 2.10.1 (R Foundation for Statistical Computing, Vienna, Austria; www.r-project.org). All reported $p$ values were two-sided, and $p<0.05$ was considered to be statistically significant.

\section{Results}

Characteristics of the study population

The demographic and clinicopathologic characteristics of these patients were shown in Table 1.

All the patients (213 men and 34 women), with a mean age of $53.27 \pm 10.33$ years, had postive HBsAg lasting for $>6$ months. All of them were Child-Pugh class A, and a small proportion had complications (17\%). As shown by the pathological results, $76(31 \%)$ patients had cirrhosis and 18 (7\%) had esophageal varices consistent with gastroscopy results. 37 (14.98\%) patients developed PHLF postoperatively, and they had a significantly higher preoperative mean LSM $(21.4 \pm 6.3 \mathrm{kPa})$ than those without PHLF $(12.7 \pm 5.7 \mathrm{kPa}, P<0.001)$.

Table 2 Univariate analysis and multivariate linear regression analysis of the variables associated with PHLF

\begin{tabular}{|c|c|c|c|c|c|c|}
\hline \multirow[t]{2}{*}{ Variables } & \multicolumn{3}{|l|}{ Univariate analysis } & \multicolumn{3}{|c|}{ Multivariate analysis } \\
\hline & $\operatorname{PLF}(+)(n=37)$ & $\operatorname{PLF}(-)(n=210)$ & p & $\operatorname{Exp}(B)$ & OR95\%Cl & $p$ \\
\hline Age (years) & $54.9 \pm 10.9$ & $53.0 \pm 10.2$ & 0.286 & & & \\
\hline Gender (Male /Female) & $33 / 4(89 \% / 11 \%)$ & 180/30 (86\%/14\%) & 0.572 & & & \\
\hline BMI (kg /m2) & $23.7 \pm 3.1$ & $23.3 \pm 3.0$ & 0.423 & & & \\
\hline White blood cell $\left(10^{9} /\right)$ & $4.9 \pm 1.5$ & $5.3 \pm 2.1$ & 0.275 & & & \\
\hline Hemoglobin (g/l) & $144.2 \pm 12.3$ & $143.8 \pm 14.4$ & 0.881 & & & \\
\hline Platelet Count $\left(10^{9} /\right)$ & $139.0 \pm 79.9$ & $155.3 \pm 56.9$ & 0.037 & & & \\
\hline Total bilirubin (umol/l) & $19.1 \pm 8.8$ & $15.4 \pm 12.2$ & 0.079 & & & \\
\hline Albumin (g/l) & $41.0 \pm 3.6$ & $41.9 \pm 3.2$ & 0.123 & & & \\
\hline Prealbumin (mg/l) & $218.2 \pm 67.9$ & $242.2 \pm 61.0$ & 0.032 & & & \\
\hline Alanine transaminase $(\mathrm{u} / \mathrm{l})$ & $43.2 \pm 31.3$ & $38.5 \pm 34.7$ & 0.449 & & & \\
\hline Aspartate aminotransferase (u/l) & $41.2 \pm 23$ & $36.1 \pm 32.4$ & 0.366 & & & \\
\hline Gamma-glutamyl transpeptidase (u/l) & $104.8 \pm 148.6$ & $68.6 \pm 69.2$ & 0.027 & & & \\
\hline Alkaline phosphatase (u/l) & $100.0 \pm 47.4$ & $83.2 \pm 23.3$ & 0.173 & & & \\
\hline $\mathrm{PT}(\mathrm{s})$ & $12.1 \pm 1.2$ & $11.6 \pm 0.8$ & 0.005 & & & \\
\hline INR & $1.0 \pm 0.1$ & $1.0 \pm 0.1$ & 0.005 & 1.065 & $1.014-1.119$ & 0.013 \\
\hline APTT(s) & $28.9 \pm 5.9$ & $27.1 \pm 5.2$ & 0.067 & & & \\
\hline LSM(kpa) & $21.4 \pm 6.3$ & $12.7 \pm 5.7$ & $<0.001$ & 1.211 & $1.134-1.293$ & $<0.001$ \\
\hline Intraoperative blood infusion (yes /no) & $7 / 30(18.9 \% / 81.1 \%)$ & $12 / 198(5.7 \% / 94.3 \%)$ & 0.005 & & & \\
\hline Portal vein occlusion (yes/no) & 24/13 (64.9\%/35.1\%) & $160 / 50(76.2 \% / 23.8 \%)$ & 0.145 & & & \\
\hline Number of tumors (Single/multiple) & $32 / 5(86.5 \% / 13.5 \%)$ & 185/25 (88.1\%/11.9\%) & 0.782 & & & \\
\hline Tumor capsule (yes/no) & $24 / 13(64.9 \% / 35.1 \%)$ & $150 / 60(71.4 \% / 28.6 \%)$ & 0.420 & & & \\
\hline HBV DNA levels $(>1.0 \mathrm{E}+04 \mathrm{iu} / \mathrm{ml} /<1.0 \mathrm{E}+04 \mathrm{iu} / \mathrm{ml})$ & 13/24 (35.1\%/64.9\%) & $60 / 150(28.6 \% / 71.4 \%)$ & 0.422 & & & \\
\hline Cirrhosis (yes/no) & $22 / 15(59.5 \% / 40.5 \%)$ & $54 / 156(27.7 \% / 74.3 \%)$ & $<0.001$ & & & \\
\hline Esophageal varices (yes/no) & $7 / 30(18.9 \% / 81.1 \%)$ & $11 / 199(5.2 \% / 94.8 \%)$ & 0.003 & & & \\
\hline Major hepatectomy & $8(22 \%)$ & $32(15 \%)$ & 0.331 & & & \\
\hline Median main tumor size $(\mathrm{cm})$ & $5.6 \pm 4.0$ & $4.9 \pm 3$ & 0.687 & & & \\
\hline Tumor location (right lobe/left lobe/both) & 29/6/2 (78.4\%/16.2\%/5.4\%) & 129/73/8 (61.4\%/34.8\%/3.8\%) & 0.082 & & & \\
\hline
\end{tabular}


Independent predictors for PHLF in HCC patients

Univariate and multivariate analysis were used for analyzing the potential influencing factors associated with PHLF, and the results were reported in Table 2.

Univariate analysis revealed that the factors including platelet count $(p=0.037)$, prealbumin $(p=0.032)$, gammaglutamyl transpeptidase $(p=0.027)$, prothrombin time $(p=0.005)$ and INR $(p=0.005)$, LSM $(p<0.001)$, the use of intraoperative blood transfusions $(p=0.005)$, the presence of cirrhosis $(p<0.001)$ and esophageal varices $(p=0.003)$ were significant predictors for PHLF.

Multivariate analysis showed that only LSM (odds ratio, OR, 1.2; 95\% confidence interval, 95\% CI, 1.134-1.293, $P<0.001)$ and INR (OR, 1.1; 95\% CI, $1.014-1.119, p<0.05)$ remained in a binary logistic regression model, and revealed they were independent risk factors for PHLF. Meanwhile, a new algorithm was defined for predicting PHLF: the LSM-INR index= $0.191 * \mathrm{LSM}+6.317 * \mathrm{INR}-11.154$.

\section{Diagnostic performance of LSM for predicting PHLF}

The diagnostic performance and corresponding ROC curves of LSM are shown in Fig. 1. The optimal cutoff value of LSM is $14 \mathrm{kPa}$ for predicting PHLF [AUC 0.860 95\% CI: 0.811-0.901, $p<0.001$; sensitivity (Se) 94.6\%, specificity (Sp) 67.6\%, positive predictive values (PPV) $34 \%$, negative predictive values (NPV) $98.6 \%$, positive likelihood ratio $\left(\mathrm{LR}^{+}\right)$2.9, negative likelihood ratio $\left(\mathrm{LR}^{-}\right)$0.1].

When considering cirrhotic patients only, ROC curve analysis identified the best cutoff value of LSM is $17.0 \mathrm{kPa}$ for predicting PHLF (AUC 0.825, 95\% CI: 0.721-

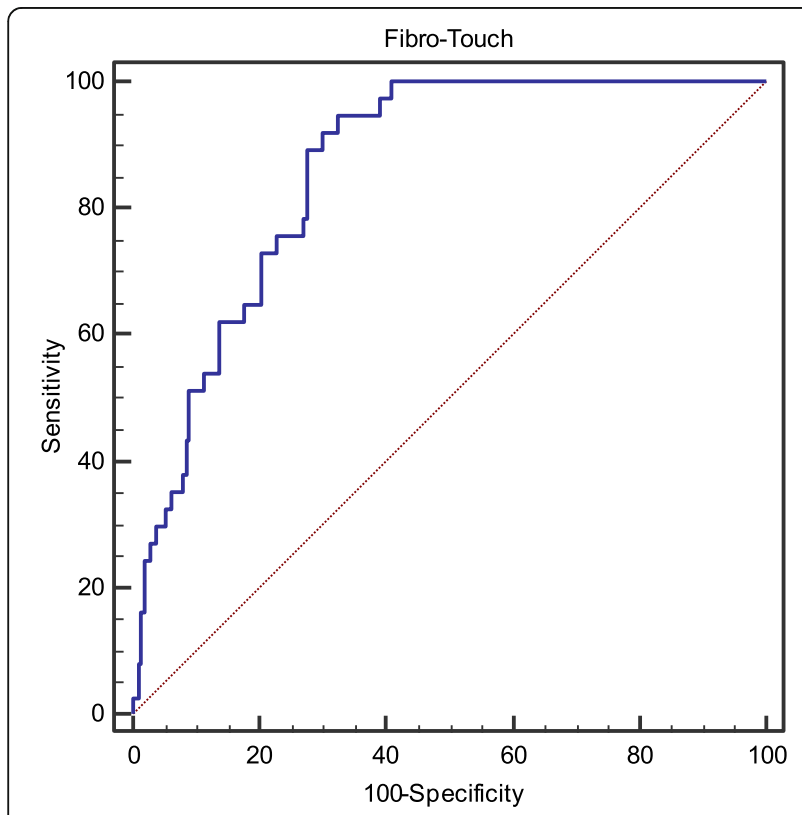

Fig. 1 ROC analysis of liver stiffness measurement for predicting PHLF
0.903, $p<0.001 ;$ Se $81.8 \%$, Sp 70.4\%, PPV 52.9\%, NPV 90.5\%, $\mathrm{LR}^{+}$2.86, $\mathrm{LR}^{-}$0.3) (Fig. 2).

Meanwhile, the optimal cutoff value of LSM is $12.8 \mathrm{kPa}$ for predicting the presence of cirrhosis (AUC 0.789, 95\% CI: $0.727-0.834, p<0.001 ;$ Se 79.0\%, Sp

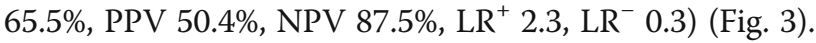

\section{Diagnostic performance of INR for predicting PHLF}

The optimal cutoff value of INR is 1.0 for predicting PHLF (AUC 0.646, 95\% CI: 0.583-0.706, $p<0.001$; Se 54.1\%, Sp 71.9\%, PPV 25.3\%, NPV 89.9\%, LR ${ }^{+} 1.9, \mathrm{LR}^{-}$ 0.6) (Fig. 4).

\section{Diagnostic performance of the LSM-INR index for predicting PHLF}

The diagnostic performance and corresponding ROC curves of the LSM-INR index are shown in Fig. 5. The optimal cutoff value of the LSM-INR index is -1.9 for predicting the presence of PHLF (AUC 0.865, 95\% CI: $0.822-0.909, p<0.001$; Se $86.5 \%$, Sp 74.8\%, PPV 37.6\%, NPV 96.9\%, $\mathrm{LR}^{+} 3.4 \mathrm{LR}^{-} 0.2$ ).

\section{Discussion}

Surgical resection is the first-line therapeutic option for early HCC [21]. However, insufficient FHR may result in postoperative complications and even PHLF (4), which is a major cause of postoperative morbidity and mortality after elective hepatic resection [22, 23].

Liver resection for $\mathrm{HCC}$ patients with chronic liver diseases still carries higher risk of PHLF than normal liver resection $[22,24]$.To the best of our knowledge, this

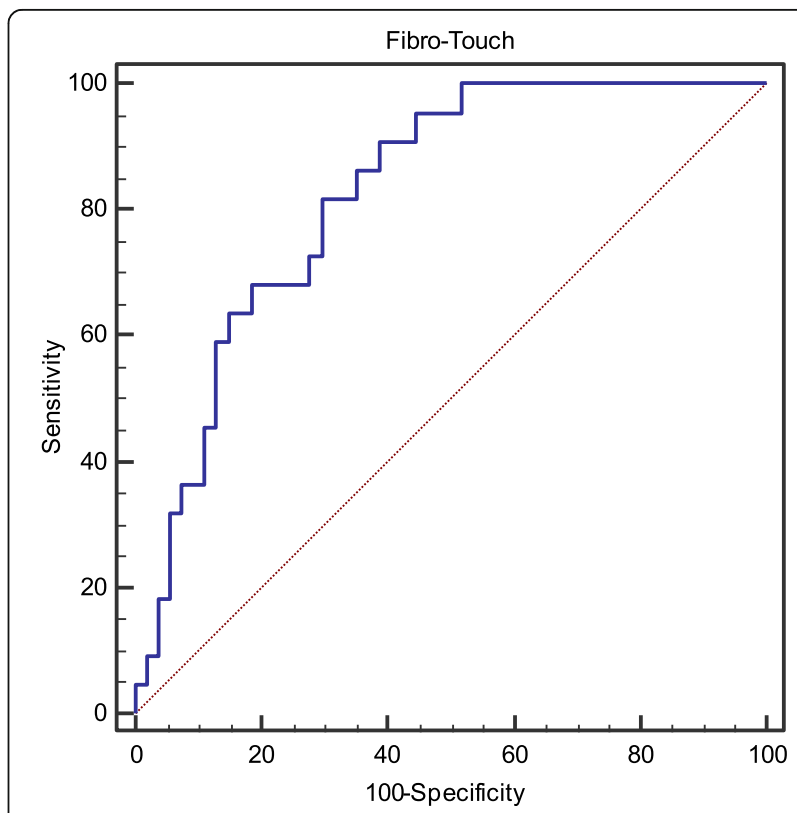

Fig. 2 ROC analysis of liver stiffness measurement with only cirrhotic patients for predicting PHLF 


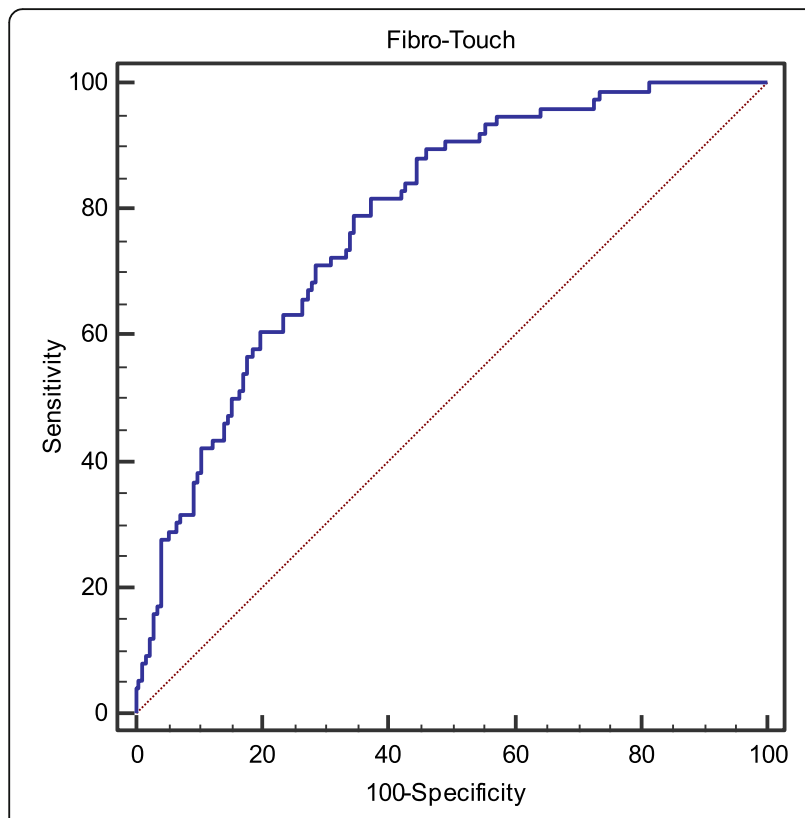

Fig. $3 \mathrm{ROC}$ analysis of liver stiffness measurement for predicting cirrhosis

is the first published study on the effectiveness of LSM measurement in predicting PHLF in patients with hepatitis $\mathrm{B}$ related hepatocellular carcinoma since previous studies only suggested a potential role of LSM in predicting postresection hepatic insufficiency. Furthermore, in those previous studies [10, 25], the background hepatic conditions causing HCC showed a great variability and included HCV, alcoholic and nonalcoholic steatohepatitis in addition to HBV. The baseline characteristics of patients differed by studies and it may result in a selection bias.

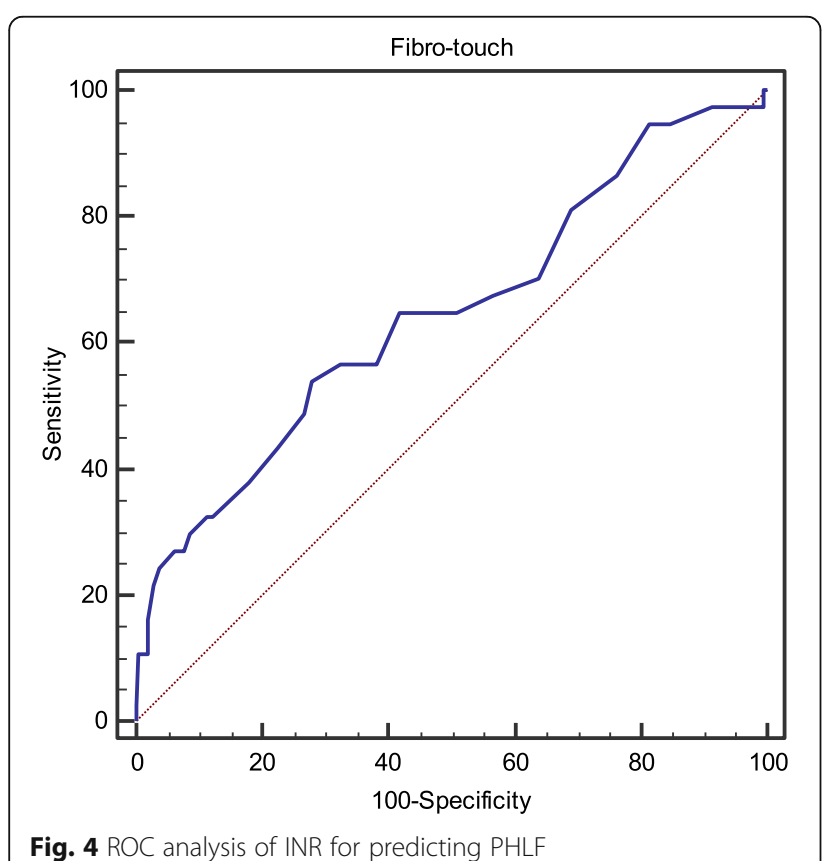

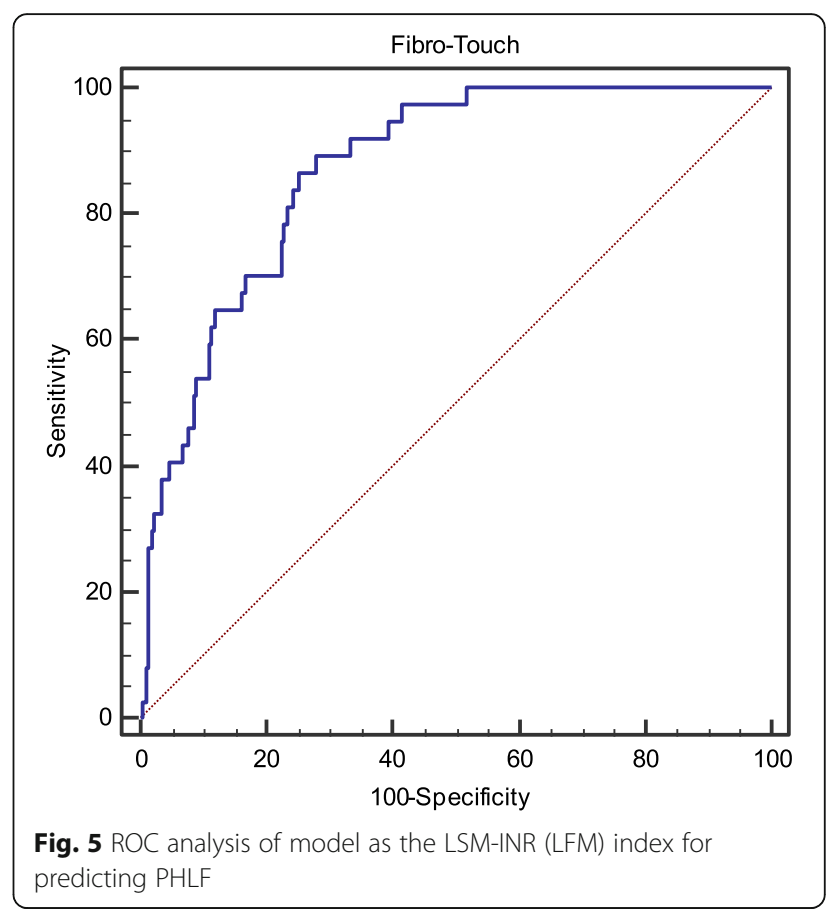

In this study, we used a new generation transient elastography, FibroTouch ${ }^{\bullet}$ for liver stiffness measurement (LSM) [9, 26], which has enhanced 2D-image-guided positioning function. It's particularly advantageous for precise preoperative examination, because the examiners are able to set the the region of interest(ROI) in the non-tumor area. It may also explain why the optimal cut-off LSM value $(14.0 \mathrm{Kpa})$ in this study is lower than that in previous studies $[10,12]$. Although the conclusions of their studies were similar to that of this study, some differences have to be pointed out. First, although the study population was very similar to ours, the background of the population was not homogenous. Secondly, their definition of PHLF was only based on postoperative serum bilirubin levels, which configures a very high risk of irreversible PHLF $(5 \mathrm{mg} / \mathrm{dL}$ for more than 5 days post operation) [27]. Perhaps for this reason, their LSM cutoff was higher and may miss milder grades of PHLF [25].

Using the calculated cutoff value of $14.0 \mathrm{Kpa}$, LSM had high specificity and negative predictive value for predicting PHLF. The value in liver failure group was significantly higher than that in non-liver failure group (21.4 Kpa vs. $12.7 \mathrm{Kpa})$. It implied that FHR may become worse with the increase of LSM value. While the effectiveness of LSM for diagnosing cirrhosis is not high (AUC $=0.78,95 \%$ confidence interval: 0.727-0.834), it may be confounded by the enrollment of patients with Child-Pugh Class A. Precisely because of this reason, one interesting result of this study is that the degree of resection is not a significant predictor of PHLF. 
In our study, HBV DNA showed no statistical differences, which is not in line with a previous report [28], and a possible explanation is the inclusion of patients with HBV DNA higher than $10^{4} \mathrm{IU} / \mathrm{ml}$. For such patients, we will first use antiviral drugs to control the amount of HBV, and then choose surgery. Univariate analysis showed that platelet count, LSM and others were significant prognostic factors for PHLF. This is consistent with the previous finding of risk factors for postoperative complications [29].

We must acknowledge this study has several potential limitations. Compared to similar articles, LSM was significantly better than ICG-15 and MELD score in the prediction of postoperative complications [10, 12], we do not routinely use ICG-15 or MELD to assess liver function. The number of the outcome of PHLF was relatively small, and further acquisition of cases and the external validation should be accomplished in the future. Second, our analysis did not include other variables that may affect the outcomes of surgery, such as the resected liver volume which is closely correlated with the functional liver reserve and postoperative results [11]. A welldesigned, well-controlled, randomized study of a large population is required.

\section{Conclusions}

In summary, our study showed that the preoperative LSM is a valid tool for surgeons in making therapeutic decisions in patients with hepatitis B related hepatocellular carcinoma. We also established a new index, LSMINR index, which quantitatively evaluated the risk of the INR and LSM that should be useful for surgeons in making therapeutic decisions in patients with hepatitis $B$ related hepatocellular carcinoma before hepatectomy.

\begin{abstract}
Abbreviations
AUC: The area under the ROC curve; EHBH: Eastern Hepatobiliary Surgery Hospital; FHR: Function of hepatic reserve; HBsAg: Hepatitis B surface antigen; HCC: Hepatocellular carcinoma; ICC: Intrahepatic cholangiocarcinoma; $\mathrm{LR}^{-}$: Negative likelihood ratio; $\mathrm{LR}^{+}$: Positive likelihood ratio; LSM: Liver stiffness measurements; NPV: Negative predictive values; PHLF: Postoperative liver failure; PPV: Positive predictive values; ROC: Receiver operating characteristic; Se: Sensitivity; Sp: Specificity; TACE: Transhepatic arterial chem otherapy and embolization; TE: Transient elastography
\end{abstract}

\section{Acknowledgements}

Not applicable.

\section{Funding}

This study was funded by the Shanghai Shenkang Hospital development Center Clinical Science and Technology Innovation Project (NO. SHDC22015004) and by the leading project of the Science and Technology Department of Fujian province (2015Y01010204)

\section{Availability of data and materials}

The data that support the findings of this study are available from [Department of Ultrasound, Eastern Hepatobiliary Surgery Hospital (EHBH), Third Affiliated Hospital of Second Military Medical University, Shanghai, China] but restrictions apply to the availability of these data, which were used under license for the current study, we will use this data for another direction and so are not publicly available. Data are however available from the authors upon reasonable request and with permission of [Department of Ultrasound, Eastern Hepatobiliary Surgery Hospital (EHBH), Third Affiliated Hospital of Second Military Medical University, Shanghai, China].

\section{Authors' contributions}

Tables and Figures were produced by $\mathrm{J}$ and $\mathrm{XJ}$ who also drafted the manuscript with equal contribution to the article; WL reviewed the literature, collected and interpreted the clinical data; $J L$ assembled and interpreted the clinical data; XJ conducted the data analysis; JL, JH, YC, YP and JG made the revision; All authors finalized the manuscript and have read and approved the final manuscript.

\section{Ethics approval and consent to participate}

The study was conducted in accordance with the Declaration of Helsinki and was approved by the Ethics Committee of Eastern Hepatobiliary Surgery Hospital, Shanghai (EHBH), NO. K2013002-P002(III). All participations were informed of the study purpose and written consents were obtained.

Consent for publication

Not applicable.

\section{Competing interests}

The authors declare that they have no competing interests.

\section{Publisher's Note}

Springer Nature remains neutral with regard to jurisdictional claims in published maps and institutional affiliations.

\section{Author details}

'Department of Ultrasound, Eastern Hepatobiliary Surgery Hospital (EHBH), Second Military Medical University, Shanghai, China. ²People's Liberation. Army Military Academy, Second Military Medical University, Shanghai, China. ${ }^{3}$ Department of Ultrasound, FuZhou General Hospital (Dongfang Hospital), Xiamen University, Fuzhou, Fujian, China. ${ }^{4}$ Department of Ultrasound, Shanghai First People's Hospital, Shanghai, China. ${ }^{5}$ Department of Ultrasound, Yuhuangding Hospital, Yantai, Shandong, China.

Received: 17 August 2017 Accepted: 15 December 2017 Published online: 29 December 2017

\section{References}

1. Shimada M, Matsumata T, Akazawa K, Kamakura T, Itasaka H, Sugimachi K, et al. Estimation of risk of major complications after hepatic resection. Am J Surg. 1994;167(4):399-403. doi:10.1016/0002-9610(94)90124-4. [PubMed: 8179084]

2. Fan ST, Lai EC, Lo CM, Ng IO, Wong J. Hospital mortality of major hepatectomy for hepatocellular carcinoma associated with cirrhosis. Arch Surg. 1995;130(2): 198-203. doi:10.1001/archsurg.1995.01430020088017. [PubMed: 7848092]

3. Schroeder RA, Marroquin CE, Bute BP, Khuri S, Henderson WG, Kuo PC. Predictive indices of morbidity and mortality after liver resection. Ann Surg. 2006;243(3):3739. doi:10.1097/01.sla.0000201483.95911.08. [PubMed: 16495703]

4. Fan ST. Liver functional reserve estimation: state of the art and relevance for local treatments: the Eastern perspective. J Hepatobiliary Pancreat Sci. 2010; 17(4):380-4. doi:10.1007/s00534-009-0229-9. [PubMed: 19865790]

5. Matsumura H, Moriyama M, Goto I, Tanaka N, Okubo H, Arakawa Y. Natural course of progression of liver fibrosis in Japanese patients with chronic liver disease type C-a study of 527 patients at one establishment. J Viral Hepat. 2000;7(4):268-75. doi:10.1046/j.1365-2893.2000.00235.x. [PubMed: 10886535]

6. Castéra L, Vergniol J, Foucher J, Darriet M, Couzigou P, De Lédinghen V. Prospective comparison of transient elastography, Fibrotest, APRI, and liver biopsy for the assessment of fibrosis in chronic hepatitis C. Gastroenterology. 2005;128(2):343-50. doi:10.1053/j.gastro.2004.11.018. [PubMed: 15685546]

7. Fraquelli M, Rigamonti C, Casazza G, Conte D, Donato MF, Ronchi G, et al. Reproducibility of transient elastography in the evaluation of liver fibrosis in patients with chronic liver disease. Gut. 2007;56(7):968-73. doi:10.1136/gut. 2006.111302. [PubMed: 17255218]

8. Friedrich-Rust M, Ong MF, Martens S, Sarrazin C, Bojunga J, Zeuzem S, et al. Performance of transient elastography for the staging of liver fibrosis: a meta-analysis. Gastroenterology. 2008;134(4):960-74. doi:10.1053/j.gastro. 2008.01.034. [PubMed: 18395077] 
9. Deng H, Wang CL, Lai J, Yu SL, Xie DY, Gao ZL. Noninvasive diagnosis of hepatic steatosis using fat attenuation parameter measured by FibroTouch and a new algorithm in CHB patients. Hepat Mon. 2016;16(9):e40263. doi:10. 5812/hepatmon.40263. [PubMed: 27822268]

10. Wong JS, Wong GL, Chan AW, Wong WW, Cheung YS, Chong CN, et al. Liver stiffness measurement by transient elastography as a predictor on posthepatectomy outcomes. Ann Surg. 2013;257(5):922-8. doi:10.1097/SLA. Ob013e318269d2ec. [PubMed: 23001077]

11. Du ZG, Li B, Wei YG, Yin J, Feng X, Chen X. A new scoring system for assessment of liver function after successful hepatectomy in patients with hepatocellular carcinoma. Hepatobiliary Pancreat Dis Int. 2011;10(3):265-9. doi:10.1016/S1499-3872(11)60044-1. [PubMed: 21669569]

12. Kim SU, Ahn SH, Park JY, Kim DY, Chon CY, Choi JS, et al. Prediction of postoperative hepatic insufficiency by liver stiffness measurement (FibroScan((R))) before curative resection of hepatocellular carcinoma: a pilot study. Hepatol Int. 2008;2(4):471-7. doi:10.1007/s12072-008-9091-0. [PubMed: 19669322]

13. Patanwala IY, Bauer HM, Miyamoto J, Park IU, Huchko MJ, Smith-McCune KK A systematic review of randomized trials assessing human papillomavirus testing in cervical cancer screening. Am J Obstet Gynecol. 2013;208(5):34353. https://doi.org/10.1016/j.ajog.2012.11.013. [PubMed: 23159693]

14. Bonino F, Arena U, Brunetto MR, Coco B, Fraquelli M, Oliveri F, et al. Liver stiffness, a non-invasive marker of liver disease: a core study group report. Antivir Ther. 2010;15(Suppl 3):69-78. doi:10.3851/IMP1626. [PubMed: 21041906]

15. Sandrin L, Fourquet B, Hasquenoph JM, Yon S, Fournier C, Mal F, et al. Transient elastography: a new noninvasive method for assessment of hepatic fibrosis. Ultrasound Med Biol. 2003;29(12):1705-13. [PubMed: 14698338]

16. Cucchetti A, Siniscalchi A, Ercolani G, Vivarelli M, Cescon M, Grazi GL, et al. Modification of acid-base balance in cirrhotic patients undergoing liver resection for hepatocellular carcinoma. Ann Surg. 2007;245(6):902-8. doi:10. 1097/01.sla.0000256356.23026.9f. [PubMed: 17522516]

17. Melendez JA, Arslan V, Fischer ME, Wuest D, Jarnagin WR, Fong Y, et al. Perioperative outcomes of major hepatic resections under low central venous pressure anesthesia: blood loss, blood transfusion, and the risk of postoperative renal dysfunction. J Am Coll Surg. 1998;187(6):620-5. doi:10. 1016/S1072-7515(98)00240-3. [PubMed: 9849736]

18. Pang YY. The Brisbane 2000 terminology of liver anatomy and resections. HPB 2000; 2:333-39. HPB (Oxford). 2002;4(2):99. author reply 99-100. [PubMed: 18332933]

19. Jarnagin WR, Gonen M, Fong Y, DeMatteo RP, Ben-Porat L, Little S, et al. Improvement in perioperative outcome after hepatic resection: analysis of 1,803 consecutive cases over the past decade. Ann Surg. 2002;236(4):397-406; discussion 406-7. [PubMed: 12368667]. doi:10.1097/00000658-200210000-00001.

20. Sugimoto H, Okochi O, Hirota M, Kanazumi N, Nomoto S, Inoue S, et al. Early detection of liver failure after hepatectomy by indocyanine green elimination rate measured by pulse dye-densitometry. J Hepato-Biliary-Pancreat Surg. 2006; 13(6):543-8. doi:10.1007/s00534-006-1114-4. [PubMed: 17139429]

21. Bruix J. M. Sherman. Management of hepatocellular carcinoma. Hepatology. 2005;42(5):1208-36. doi:10.1002/hep.20933. [PubMed: 16250051]

22. Belghiti J, Hiramatsu K, Benoist S, Massault P, Sauvanet A, Farges O. Seven hundred forty-seven hepatectomies in the 1990s: an update to evaluate the actual risk of liver resection. J Am Coll Surg. 2000;191(1):38-46. [PubMed: 10898182]

23. Wang Q, Lau WY, Zhang B, Zhang Z, Huang Z, Luo H, et al. Preoperative total cholesterol predicts postoperative outcomes after partial hepatectomy in patients with chronic hepatitis B- or C-related hepatocellular carcinoma. Surgery. 2014; 155(2):263-70. doi:10.1016/j.surg.2013.08.017. [PubMed: 24569301]

24. Fan ST. ProbLSM-INR indexs of hepatectomy in cirrhosis. HepatoGastroenterology. 1998;45(Suppl 3):1288-90. [PubMed: 9730390]

25. Cescon M, Colecchia A, Cucchetti A, Peri E, Montrone L, Ercolani G, et al. Value of transient elastography measured with FibroScan in predicting the outcome of hepatic resection for hepatocellular carcinoma. Ann Surg. 2012; 256(5):706-712; discussion 712-3. [PubMed: 23095613]. doi:10.1097/SLA. Ob013e3182724ce8.

26. Yuan L, Shao J, Hao M, Li C, Wang G, Wang T, et al. Correlation between liver hardness testing results obtained by FibroTouch and FibroScan and liver pathological stage. Zhonghua Gan Zang Bing Za Zhi. 2014;22(6):425-9. [PubMed: 25203705]

27. Balzan S, Belghiti J, Farges O, Ogata S, Sauvanet A, Delefosse D, et al. The "50-50 criteria" on postoperative day 5: an accurate predictor of liver failure and death after hepatectomy. Ann Surg. 2005;242(6):824-828, discussion 828-9. [PubMed: 16327492]. doi:10.1097/01.sla.0000189131.90876.9e.
28. Huang G, Lau WY, Shen F, Pan ZY, Fu SY, Yang Y, et al. Preoperative hepatitis $B$ virus DNA level is a risk factor for postoperative liver failure in patients who underwent partial hepatectomy for hepatitis B-related hepatocellular carcinoma. World J Surg. 2014;38(9):2370-6. doi:10.1007/ s00268-014-2546-7. [PubMed: 24696061]

29. Capussotti L, Muratore A, Amisano M, Polastri R, Bouzari H, Massucco P. Liver resection for hepatocellular carcinoma on cirrhosis: analysis of mortality, morbidity and survival-a European single center experience. Eur J Surg Oncol. 2005;31(9):986-93. doi:10.1016/j.ejso.2005.04.002. [PubMed: 15936169]

\section{Submit your next manuscript to BioMed Central and we will help you at every step:}

- We accept pre-submission inquiries

- Our selector tool helps you to find the most relevant journal

- We provide round the clock customer support

- Convenient online submission

- Thorough peer review

- Inclusion in PubMed and all major indexing services

- Maximum visibility for your research

Submit your manuscript at www.biomedcentral.com/submit
C Biomed Central 